\title{
Interpretations on the Abnormal Characters in the Novels by Lao She
}

\author{
Dan $\mathrm{Li}^{1}$ \\ ${ }^{1}$ Literature Institute, Changchun University of Science and Technology, Changchun, China \\ Correspondence: Dan Li, Literature Institute, Changchun University of Science and Technology, 7089 Weixing \\ Road, Changchun 130022, China. Tel: 86-136-0441-3902. E-mail: lidan5858@hotmail.com
}

Received: August 5, 2012 Accepted: August 21, 2012 Online Published: November 30, 2012

doi:10.5539/ass.v8n15p235 URL: http://dx.doi.org/10.5539/ass.v8n15p235

\begin{abstract}
Lao She's novels describe the class of common citizens and create many kinds of figures. Among these characters, there are one kind that shows abnormal life states and attitudes without any exceptions in that complicated society, although they have different identities and personalities. By analyzing the reasons for the formation of abnormal psychology of these people, the author categorizes these figures into three types: the first is the self-reclusive abnormal psychology; the second is the institutional- closed abnormal psychology; the third is the abnormal psychology caused by pursuit for self interests. By means of categorization, the author hopes to interpret Lao She's wishes for reforming the characters of nationals.
\end{abstract}

Keywords: Lao She, novel, abnormal character

During the period from 1920s to 1930s, China has suffered from the imperialist countries' political, economical, military, and religious infiltration and erosion, and the soak of previous feudal traditions, together with the influences and the promotions of Chinese intellectuals' various temptations in saving the country's economy, military, politics, culture, and many other aspects. Accordingly, the common citizens in China show colorful spirits and characters. Lao She's works always care about the actual life of common people and the fate of nation. One aspect proving this cares of Lao She in his novels is the description of common citizens' spirits and fates. Among these characters, there is one kind that deserve out attentions. Although they have different identities and personalities, they are living abnormal lives with abnormal life attitudes, without any exceptions, in that complicated society. Here, the author categorizes these characters into four types and makes some analyses in this paper.

\section{The Self-reclusive Abnormal Psychology}

Lao She creates a series of awakening figures. In particular, there is one kind of characters who are also awakening, but they cannot bear the sadness of desperation after the awakening and choose to be self-reclusive. This closure causes their extremely complicated and contradictory attitudes. In this contradictory state, they gradually develop the nearly self-killing abnormal psychology. The representatives of this kind of characters are Mr. Cao in Rickshaw Boy and Ruixuan Qi in Four Generations under One Roof.

In the Rickshaw Boy, Xiangzi has had a pleasant garden originally. The founder of the pleasant garden was Mr. Cao. In the eyes of Xiangzi, Mr. Cao was a great person who could save life and give hope. However, as a matter of fact, Mr. Cao was nothing but name himself as a socialist. After he heard that he was turned in by Ming Ruan for the crime of tutor of revolution, he felt funny and he knew how much his socialism was incomplete. As Mr. Cao was followed closely by a detective, he hated himself for not being a warrior. He saw through himself and the society, but he finally fled to a left government in order to save his life. Mr. Cao could not save the life of Xiangzi. Even the degenerated Xiangzi signed and talked to himself.

Ruixuan Qi in Four Generations under One Roof was an intellectual living in the transition period of the old times to the new times. On one hand, he took traditional culture education in his childhood. On the other hand, he undertook western modern civilization and new education. The two aspects made Ruixuan become a special contradictory individual at that time. Concerning his marriage, although he deeply knew that the relationship should be free and the marriage should be domestic, he finally followed the filial piety and married the virtuous Yunmei to satisfy his grandparents and parents. As a traditional wife, Yunmei was impeccable, but she would never understand him or make spiritual communication with him. The awakening of national consciousness gave Ruixuan a heart with sincere love to his motherland. He understood the essence of "rise of fall of the world, 
everyone is responsible for". He hoped to take the responsibility of saving the country. However, the heavy burden from his four-generation families was like a rope, circling him tightly. He could not leave his family and ran for the battlefield against the Japanese invaders. He suffered a lot due to the conflict between serving the family and fighting for the country. His pains were based on the clear understandings of human consciousness and national dignity, which gave his soul more burdens.

\section{The Institutional-closed Abnormal Psychology}

Under the rule of feudal despotism, the people were not allowed to express their views. All activities must strictly follow the regulations set by the feudal rulers. Humanities were severely restricted and depressed. Normal humanities have been distorted and become abnormal, which would inevitably cause people's ignorance and numbness. The representatives of this kind of figures are the Mr. Ma elder in the Mr. Ma Elder and Mr. Ma Junior and Tianci Niu in the Legend of Tianci Niu.

Tianci in the Legend of Tianci Niu was an abandoned baby, who was adopted by the Niu family by name Tianci Niu. The Niu family had no heirs. After Tianci entered the Niu home, he stepped into the traditional Chinese feudal track. When he was still in its infancy, his hands and feet were tied up in a long period because of the goodwill of the old Mrs. Niu and the fear of him with bandy legs. In his childhood, he had to obey numerous rules and regulations. Except being obedient, he learned nothing but fool and perfunctory. After leaving the home, he suffered more: schools and society were polluted by evils; students were competing for the status or the money of the family; tutors maintained the order by beating students; the class adviser casually said that nothing matters and do not be serious as lecturing to the students. Because Tianci was lack of a normal childhood to raise his nature, it was impossible for him establishing morals and training characters. During the short period of one decade, Tianci experienced the whole process, in which his naïve soul was completely swallowed by levels of corrupted and declined social cultures. He even came to realize that he was a little waste without any strength and incapable of nothing.

The Mr. Ma elder in the Mr. Ma Elder and Mr. Ma Junior was always wondering around in his life. When he was in school, he had bad grades. After the graduation, he was busy in marrying and giving a birth to kids. He had no skills but he was lazy and greedy. He could do nothing but lived the life on his inherited estates with helps of his older brother. He despised businessman to a great degree and always dreamed of being an officer. After arriving London, he ruined the antique shop from his older brother soon. He still had the concept of country, but he did not understand what the country was. What he wanted was nothing but being an officer, but he knew nothing about the responsibility of being an officer. The Mr. Ma elder was the victim under the rule of feudal autocracy.

In creating this kind of figures, what Lao She's accusation was pointing at not only the common citizens as victims, but also the feudal despotism, what reigned over the people for a long period and caused the bad consequence. Under the rule of feudal despotism, humanities suffered from severe restriction and depression. Normal humanities were distorted and became abnormal. Lao She used his novels to help people realize the destruction of feudal despotism on humanities.

\section{The Abnormal Psychology Caused by the Pursuit for Self Interests}

This kind of characters swallowed others' interests and happiness and even wills as they were realizing their values and pursuing self interests. The representatives of this kind of characters are Si Liu, Huniu, and Ming Ruan in the Rickshaw Boy.

Si Liu in the Rickshaw Boy was clever enough to pursue his happiness in life. When he was young, he robbed families, traded persons, raped nice women, and built his happiness on the sufferings of kind people. When he was old, he changed himself and lived a normal life. He started a business with employees and cars. At that time, the accumulation of his money was based on sacrificing the marriage and the happiness of his daughter Huniu. Although he felt guilty sometimes, he felt that Huniu was so useful that he did not want her to get married. Therefore, he became so angry that he cut the relationship with Huniu, when he knew that Huniu and Xiangzi were married quietly. He even sold his business and enjoyed his life with the money.

Huniu was the daughter of Si Liu, the owner of the rickshaw business. She was ugly, wild, cunning, as well as shrewd and competent. She helped his father run and mange the rickshaw business. However, the extremely greedy and selfish Si Liu could not make her feel any warmth of family. Furthermore, Si Liu did not allow Huniu to marry anybody in order to keep the cheap and useful helper. Unfortunately, the 35-year-old Huniu was still out of a happy marriage. She seized an opportunity to seduce, threaten, and lie to Xiangzi. Finally she forced Xiangzi to marry her by all means. In marriage, she still had the complete control over Xiangzi and never 
thought about his feelings. What she rapped was not only Xiangzi's body, but also his dream of fighting for freedom and independence, forming a family, starting a career by hard work.

Ming Ruan was a progressive youth in the Rickshaw Boy. Compared with Mr. Cao, a socialist, Ming Ruan was more progressive. He was always talking about his ambition but without any skills or competence. He flattered his teacher, Mr. Cao, merely for the sake of passing the test. When his trick was not successful, he turned back to Mr. Cao and reported to the party against Mr. Cao. He said Mr. Cao promoted some progressive thoughts among students in order to revenge Mr. Cao as well as enter a new party by this way. He discarded his thoughts and became an officer. He really enjoyed his new life that was supposed to be cursed and abandoned by him previously. However, a luxury life needed money. Ming Ruan spent money as much as he wanted, without any plans. When he could not make ends meet, he began to get money by using his long-abandoned thoughts.

The abnormal figures in Lao She's novels had different identities. Their abnormal psychology was triggered by different reasons and produced different harms to the society. However, they all reflected the abnormal psychology of national citizens caused by the complicated social state at that time, without any exceptions. By describing the abnormal psychology of this kind of figures and analyzing the causes, Lao She tried to fulfill his wishes for changing and reshaping the national character.

\section{References}

Godwin, W. (1980). Enquiry Concerning Political Justice (Vol. 2-3). Beijing: The Commercial Press.

Lao, S. (1999). Complete Works of Lao She. Beijing: People's Literature Publishing House.

Lao, S. (1999). Literature creation. Complete Works of Lao She (Vol. 16). Beijing: People's Literature Publishing House.

Pei, Y. R. (2000, September). Chinese Literature Humanity History of 20th Century (1st ed.). Shanghai: Shanghai Bookstore Publishing House. 